\title{
Influence of cavitation on pressure pulsation through impeller of large pumps
}

\author{
Rustam Ergashev ${ }^{1 *}$, Azam Azimov ${ }^{1}$, Boybek Kholbutaev ${ }^{2}$, and $L$ Mavlonov ${ }^{1}$ \\ ${ }^{1}$ Tashkent Institute of Irrigation and Agricultural Mechanization Engineers, Tashkent, Uzbekistan \\ ${ }^{2}$ Jizzakh Polytechnic Institute, Jizzakh, Uzbekistan
}

\begin{abstract}
The article provides the main recommendations for studying the processes of cavitation development on the models of pumping units OPV-10-260 and V 20-13/45 with an impeller diameter $D_{\mathrm{r}}=250 \mathrm{~mm}$. The nature of the effect of cavitation depends on forms of pressure pulsation. The purpose of this work is to study abrasive-cavitation erosion of large pumps. The research objectives are to develop a methodology for calculating their operating modes, taking into account the minimum deterioration of working parts. Strongly developed cavitation leads to disruption of regular pulsations and an increase in the swing of the highfrequency component. Investigations of operating mode of pumps with deterioration of elements of flow section were carried out, and the characteristics of materials for the manufacture of hydromechanical equipment for resistance to cavitation deterioration were refined. According to experiments, the influence of pressure on the pressure fluctuation range begins to significantly affect if the pump pressure is less than $5 \mathrm{~m}$. The nature of the effect of cavitation depends on the forms of pressure pulsation. The complexity of composition, high cost of high-alloy steels, and non-ferrous alloys make it irrational to use them in massive parts operating under cavitation-abrasive conditions. It is recommended to use the developed dependencies on machine water elevating systems to reduce deterioration by improving the quality of impeller materials.
\end{abstract}

\section{Introduction}

Reforms in agriculture and water management in Uzbekistan envisage the commissioning of hundreds of thousands of hectares of a new irrigated field. In solving these problems, a large role is assigned to pump irrigation. Hundreds of thousands of hectares of a field in the Karshi steppe have been developed by constructing large pumping stations (PS) equipped with unique axial pumps with an impeller diameter of $2600 \mathrm{~mm}$ and a water supply of up to $40 \mathrm{~m}^{3} / \mathrm{s}$. Currently, there are large PS Sherabad, Kuyumazar with axial pumps, Amubukharsky, Jizzakh, Amuzang, and others with similar parameters for large vertical centrifugal pumps $[1,2]$. Surveys of operation of large pump stations in Uzbekistan have established that pump flow sections are subject to intense cavitation deterioration. The

\footnotetext{
*Corresponding author: jaloliddin5@mail.ru
} 
water elevated over by pumps contains various mineral salts and suspended solids, which accelerate joint cavitation and corrosion, deterioration. Improving the durability and stability of large irrigation pumps while rebuilding their worn-out areas is a major challenge.

\section{Methods}

When writing this article, the theory of vane pumps and cavitation-abrasive deterioration of metals in the flow section of pumps was used. During the experimental studies, standard pump test methods were used. The choice of material for the restoration of worn-out pump parts is based on gravity's local load application characteristic.

\section{Results and Discussion}

In many cases, cavitation phenomena in the area of the pump impeller have a great influence on deterioration and pressure pulsation. From the point of view of reliability obtained experimental data, it is of interest to assess the measure of the influence of these phenomena on characteristics of non-stationary. How to recalculate the data of a model experiment to nature is one of the main ones in the study of unsteady processes in the flow section of pumps. Analysis of literature sources shows that temporal characteristics of periodic processes - frequency or period - obey the similarity in terms of reduced frequency, and pressure pulsation ranges can be recalculated for isogonal modes in proportion to the pressure $[3,4]$. However, the extent to which this rule applies has not been specifically investigated. Knowledge of the dependence of pressure pulsation on pressure head and the cavitation coefficient allows one to build a methodology for the corresponding experiments and reasonably recalculate their data to nature. We will conclude that the unsteady motion of water through the flow section obeys the Navier-Stokes equation $[5,6]$. Assuming that gravity does not determine the nature of such a flow (cases of the influence of wave processes in the headwaters of the hydroelectric complex are excluded), we write this equation in the form

$$
\frac{\partial \overline{\mathrm{V}}}{\partial \mathrm{t}}+(\overline{\mathrm{V}} \nabla) \overline{\mathrm{V}}=-\frac{1}{1 \rho} \operatorname{gradp}+v \Delta \overline{\mathrm{V}}
$$

Where $\overline{\mathrm{V}}$ is flow velocity vector; $\mathrm{p}$ is pressure; $p$ is density; $v$ is kinematic viscosity; $t$ is time.

Introducing dimensionless speed $V^{\prime}$, pressure $\mathrm{p}^{\prime}$ and time $\mathrm{t}^{\prime}$, write the equation (1), in dimensionless form

$$
\operatorname{Sh} \frac{\partial\left(\bar{j} v^{\prime}\right)}{\partial t}+\left(j v^{\prime} \nabla\right) \bar{j} v^{\prime}=-E u \operatorname{grad} p^{\prime}+\frac{1}{\operatorname{Re}} \Delta \bar{j} v^{\prime}
$$

where $\overline{\mathrm{j}}$ is unit velocity direction vector $\bar{V} ; \mathrm{Sh}=\frac{L}{\mathrm{VT}}$ is Strouhal number; $\mathrm{Re}=\frac{V L}{v}$ is Reynolds number; $\mathrm{Eu}=\frac{\Delta \rho}{\rho \mathrm{V}^{2}}$ is Euler's number.

The unsteady process is assumed to be periodic. Then the condition for the similarity of 
flows will be satisfied if

$$
\begin{gathered}
S h=i d e m ; \\
R e=i d e m ; \\
j=i d e m .
\end{gathered}
$$

The last condition means the geometric similarity of the speed plans. The consequence of these three conditions is $E u=i d e m$.

If the unsteady flow is the result of the addition of several periodic forms, then it follows from the generality of Eq. (1) that for such flow components with some characteristic velocities $v_{0 i}$, the condition will be automatically met $\frac{v_{0 i}}{v_{0}}=i d e m$ and the constancy of the ratio of the corresponding Strouhal numbers, one of which should be taken as the "main" number $\mathrm{Sh}_{\mathrm{o}}$.

When testing pump models, the main unsteadiness created by the impeller vane system in absolute motion is characterized by the Strouhal number $\mathrm{Sh}_{0}$, which is related to the reduced speed $\mathrm{n}_{I}^{\prime}$ relation $[7,8]$

$$
\mathrm{Sh}_{\mathrm{o}}=\sqrt{\frac{R}{\mathrm{E} u}} \mathrm{n}_{I}^{\prime}
$$

If the flow moves within the framework of equation (1), the characteristic periods of pressure pulsation should be in a constant ratio

$$
\begin{aligned}
\lambda & =\frac{D_{I}}{\mathrm{~T} \sqrt{\mathrm{H}}} \\
\tau & =\frac{\mathrm{T} n}{60}
\end{aligned}
$$

where $D_{I}$ is impeller diameter; $T$ is characteristic period of a non-stationary process: $H$ is installation head; $n$ is impeller speed; $\lambda$ is reduced frequency; $\tau$ is relative period.

Simulation of working processes of pumps is performed so that only the condition $n^{\prime}=i d e m$ (that is $S h_{o}=i d e m$ ), the condition $R e=i d e m$ usually violated. Strictly speaking, this should lead to the fact that the condition $E u=i d e m$ also shouldn't be executed. However, consideration of equation (2) shows that for some numerical ratios between the coefficients, this equation can be invariant concerning scales if only the first and third of the criteria (3) are satisfied.

Number $R e$ will not affect the solution of the equation (1) when the viscosity is low, that is not enough $v$, but even then, when $\mathrm{R} e$ is very large, that is the last term of the equation (2) will be small compared to the rest of the members. This implies the admissibility of different values of the number Re for the model and nature, provided that in both cases, it is large enough (the condition of self-similarity).

If pressure pulsation is caused by phenomena not described by equation (1) (cavitation processes, discontinuous flows), then the fulfillment of similarity conditions (3) turns out to be insufficient. For example, for cavitation phenomena, it is also necessary to comply with the known condition $\sigma_{y}=$ const $[9,10]$.

To find out to what extent violation of the conditions of similarity in numbers Re and 
$\sigma$ affects the magnitude of pressure pulsation in the laboratory of PS Scientific Research Institute of Irrigation and Water Problems, an experimental study was carried out.

Number Re changed by changing the head of the installation while observing isogonal modes. The pressure pulsation was measured on the cone walls and in the inlet section of the bend of the suction pipe (Figure 1).
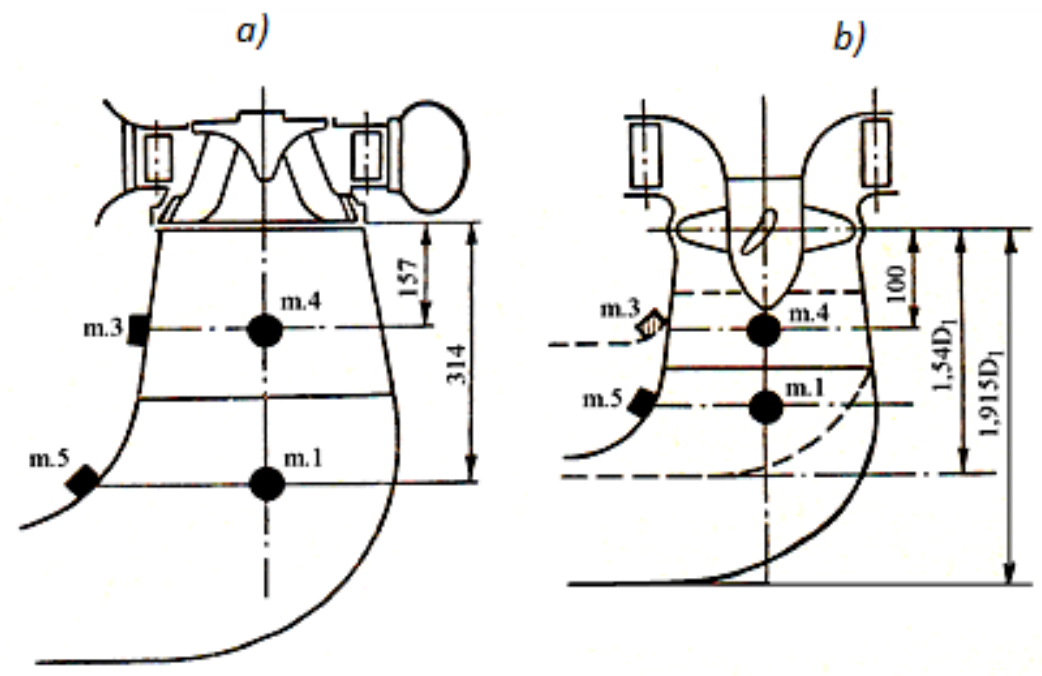

Fig. 1. Pressure pulsation measurement points: a) type B pump impeller; b) OPV impeller

Of the various forms of pulsation, the most detailed study was made of its low-frequency form, which appeared in the presence of a positive swirl of flow. The studies were carried out on a model of an impeller $\mathrm{D}_{1}=250 \mathrm{~mm}$. The change in Reynolds number was carried out by changing the pressure at $n_{I}^{\prime}=$ const. The pressure pulsation was measured using strain gauge pressure sensors with a membrane diameter of $30 \mathrm{~mm}$. Oscillograms were processed by a statistical method to determine the average range of pressure pulsations $\bar{p}$. The relative pulsation swing was obtained by dividing the swing by the head $\mathrm{p}_{I}^{\prime}=\frac{\Delta \rho}{\mathrm{H}}$, and the relative period was calculated by the formula (5).

In all cases, with a change in the head, the pressure downstream of the installation changed in such a way as so that $\sigma_{y}=$ const. In total, from 3 to 5 operating modes were investigated for various types of impellers. The head varied from 4 to $15 \mathrm{~m}$ for the axial impeller and from 15 to $60 \mathrm{~m}$ for the centrifugal one for each of them. The results are shown in figure 2. 


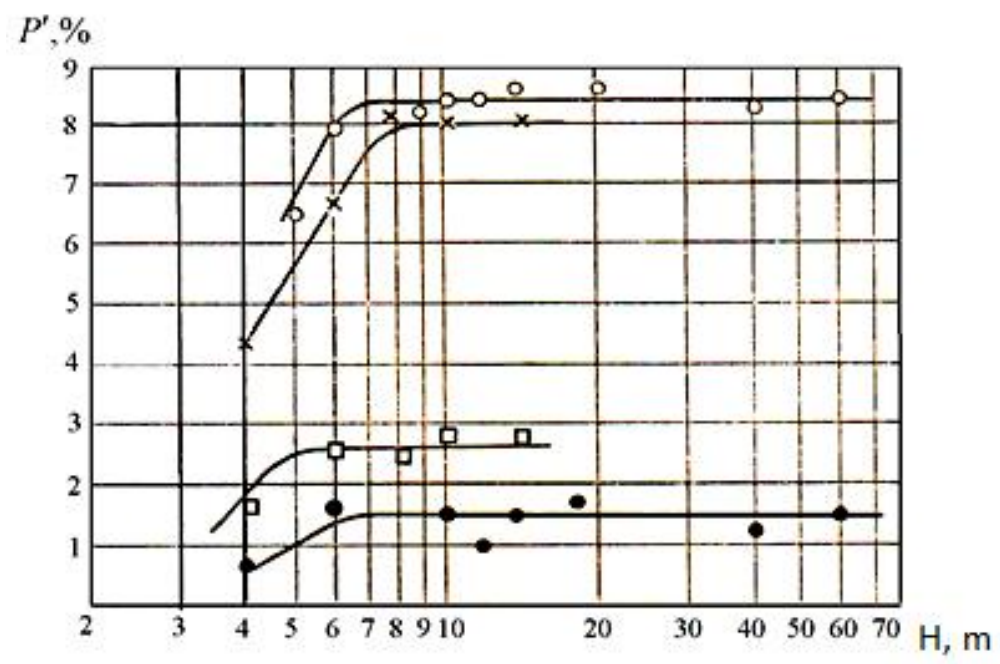

Fig. 2. Change to amplitude of pressure pulsation depending on pressure

Figure 2 shows the measurement data: $\mathrm{x}$ is OPV-10-260 impeller (PS 2-6 KMC), propeller mode when $\varphi_{0}=+2^{\circ}$, is impeller OPV-10-260, combinatorial mode at $\varphi_{0}=+0^{\circ}$, $\mathbf{0}$ is impeller V 20-13/45 (PS "Khiziltepa" and "Amubukhara -2") is low-frequency form; • is impeller V 20-13/45 is high-frequency form.

Change in low-frequency pressure pulsation occurring with a relative period $\mathrm{T}=3 \div 5$ impeller revolutions satisfies the condition well $\mathrm{p}_{I}^{\prime}=$ const, if the head of the installation exceeds $5 \mathrm{~m}$. High-frequency pressure pulsation with a relative period $\mathrm{T}=0,1+0.05$ revolutions and higher at pressures less than $7 \mathrm{~m}$ revealed a deviation from the law $\mathrm{p}_{I}^{\prime}=$ const.

The study dependence, amplitude, pressure pulsation, and frequency on change in the cavitation coefficient of installation were carried out on the same stand [11,12]. At the same time, the task was to obtain data on the degree of influence of cavitation phenomena in the flow section of the pump on non-stationary processes. In these tests, along with obtaining the usual breakaway cavitation characteristic, pressure pulsations were recorded at the points shown in Figure 1.

It was found that low-frequency pressure pulsation $(T=3 \div 5)$ practically does not depend on the value of the cavitation coefficient of installation $\sigma_{\mathrm{y}}$, if the latter exceeds the value $\sigma_{\mathrm{KP}}$ on $20-30 \%$ and more (Fig. 3). Pressure pulsation was also observed when the pressure under the impeller increased so much that the visible vortex cord was no longer noticeable. This suggests that this type of pressure pulsation is determined by the kinematics of flow (for example, swirl and not cavitation phenomena).

This figure 3 shows data from the impeller test results V 20-13/45. 
a)

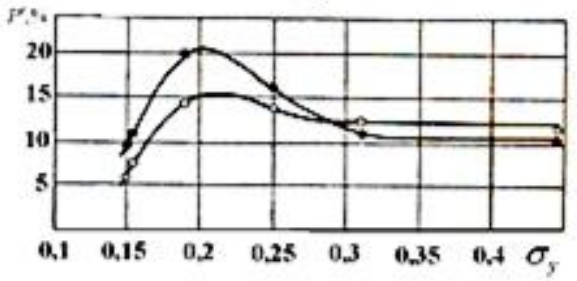

b)

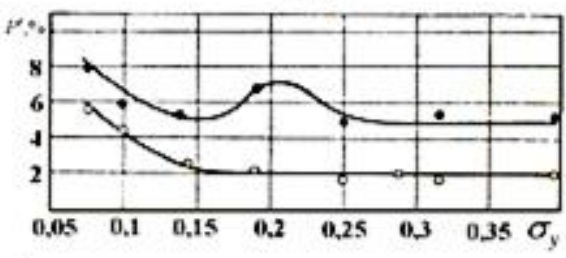

v)

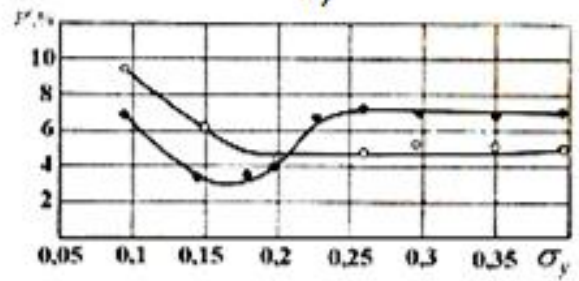

Fig. 3. Change in the relative range of pressure pulsations depending on $\sigma_{\mathrm{y}}$. Impeller V20-13/45: a) $a_{o}=14 \mathrm{~mm}$, (low frequency form); b) $a_{o}=18 \mathrm{~mm}, \mathrm{v}$ ) $a_{o}=22 \mathrm{~mm}$, (irregular form); $\bullet$ is measuring point 5 ; o is measuring point 3 .

Irregular pressure pulsation changes similarly (figure 3, b). Tests V14-14/65 showed similar dependencies.

Cavitation in a liquid medium is a process of formation of ruptures (caverns) under the influence of tensile stresses arising in a zone of low pressures. With the subsequent movement of cavitation bubble and high-pressure zone, rapid destruction (compression) occurs, leading to the occurrence of a hydrodynamic shock, causing material deterioration [13-15]. Despite the presence of aggressive mineral salts in the elevated-over water, the main cause of cavitation wear is not corrosive but mechanical action (Table 1).

Table 1. Rate of cavitation and corrosive deterioration of materials

\begin{tabular}{|c|l|c|c|c|}
\hline \multirow{2}{*}{ № } & \multirow{2}{*}{ Material name } & \multicolumn{2}{|c|}{$\begin{array}{c}\text { Length of the cavitation } \\
\text { zone, } \\
\text { mm after } 12 \mathrm{~h}\end{array}$} & \multirow{2}{*}{$\begin{array}{c}\text { Weight loss } \\
\text { mg after } 12 \\
\text { hours }\end{array}$} \\
\cline { 3 - 4 } & & $\begin{array}{c}\text { in case of } \\
\text { cavitation }\end{array}$ & $\begin{array}{c}\text { in case of } \\
\text { corrosion }\end{array}$ & \\
\hline 1 & Gray cast iron GCI-20 & 18 & 0.3 & 220.0 \\
\hline 2 & Carbon steel or simple steel & 9 & 0.15 & 95.0 \\
\hline 3 & stainless steel alloy $(\mathrm{Cr} 18 \% ; \mathrm{Ni}-8 \%)$ & 2 & 0.001 & 13.0 \\
\hline 4 & Cast stainless steel alloy $(\mathrm{Cr}-12 \%)$ & 3 & 0.009 & 20.0 \\
\hline 5 & Brass & 7 & 0.03 & 145.0 \\
\hline
\end{tabular}

The table shows that the rate of corrosive deterioration is many times lower than that cavitation. The highest resistance to cavitation wear among the given structural materials is stainless steel. The impeller blades of axial-flow pumps are destroyed by surface cavitation from the suction side. In this case, deterioration increases towards the peripheral ends of blades. Crevice cavitation occurs due to a sharp increase in the flow rate in various types of slots and gaps. The most typical example of deterioration caused by crevice cavitation is the deterioration of walls of chambers or water flow sections and the peripheral ends of axial pump blades. Due to cavitation wear of the flow section of pumps, the characteristics of pumps deteriorate. The decrease in the pump efficiency caused by an increase in the energy consumption during the 
overhaul period of the pump operation can reach $6-7 \%$ of the total amount of consumed electricity. Considering that the cost of electricity for pumping stations reaches $90 \%$ of total operating costs, it becomes clear that maintaining high efficiency of equipment is of great importance for economical operation of pumping stations. Thus, correct determination of optimal duration of overhaul period for the operation of pumps operating under conditions of intense cavitation wear can significantly weaken its negative consequences. Martensite has the highest resistance to cavitation. It is possible to use maraging steels to use a martensitic structure to obtain maximum resistance to cavitation erosion while maintaining the structural strength of parts of even large sections. A feature of these steels is a high nickel content and a low carbon content (about $0.03-0.05 \%$ ), making it possible to obtain carbon-free soft martensite during quenching. The correct choice of the composition of maraging steel and the heat treatment regime provides the necessary set of mechanical properties, good machinability, weldability, and high resistance to cavitation erosion. To obtain a cavitation-resistant structure of martensite, another way can be chosen: the use of unstable austenitic steels that decompose under the influence of deformation with martensite formation. Iron-based austenitic alloys contain large amounts of nickel and manganese. Their characteristic feature is intense hardening under micro-shock action and the formation of deformation martensite. Observations carried out under the conditions of waterjet deterioration show that alloyed steels are more resistant to suspended sediment than carbon steels [16-24]. In this respect, they are preferred, as is the choice of material for parts subject to waterjet erosion.

According to the Research Institute of Irrigation and Water Problems, the abrasive deterioration resistance of cast iron can vary widely depending on its chemical composition and processing method [25-37].

Suppose the deterioration resistance of gray cast iron is relatively low. In that case, alloys of white cast iron and heat-treated high-chromium cast iron are better than carbon steels regarding their resistance to abrasive deterioration. Internal surfaces of chambers and impellers are subject to the most severe destruction. Due to the separation of the flow caused by the mismatch between the angle of incident flow and the angle of installation of the blades, their increased destruction is possible. The pump deterioration on the Shafrikanskaya branch of the PS Kiziltepa is shown in Figure 4 a.


Fig. 4. a) Deterioration of impellers on the PS Kiziltepa, b) a new impeller on the Shafrikan branch of the PS Kiziltepa

On the pump V14-14/65 of the Shafrikan branch of the PS Kizil-Tepa, the material of the impellers ST 10x18N3G3D2L, casing cover, and bearings ST 25L-II. The measurements carried out with the Metuda hardness meter (Russia) showed that the deterioration of the impellers on the Shafrikanskaya branch of the PS Kizil-Tepa was at a hardness of 284 on the new impeller -323 (Figure 4 b) casting on the body PU (volute) -155 . The deterioration of the impellers on the Kharkhur branch of the PS Kiziltepa was at a hardness of 344, on the new impeller -367 , on the body (volute) -171. This hardness was chosen due to the need to improve the parameters of the Austrian "ANDRITS" pump [20, 21]. 


\section{Conclusions}

1. Investigations of the operating mode of pumps with deterioration of parts of the flow section were carried out. The characteristics of materials for the manufacture of hydromechanical equipment for resistance to cavitation wear were refined. For unsteady pressures in the flow section of the pumps, the conditions $\tau=$ const and $\mathrm{p}^{\prime}=$ const models and natures are provided if the conditions are met for isogonal modes and $\mathrm{Re}=$ const. The last condition can be violated if the Re numbers are large enough.

2. According to experiments, the influence of the head on the pressure fluctuation range begins to significantly affect if the pump head is $\mathrm{H}<5 \mathrm{~m}$. Thus, it is advisable to study unsteady processes on models with an impeller diameter $\mathrm{Dr}=250 \mathrm{~mm}$ at pressures less than $5 \mathrm{~m}$; otherwise, the values of swinging pulsating pressures will be underestimated.

3. The influence of the cavitation coefficient on the range and frequency of pressure pulsations in the suction pipe begins to affect when $\sigma_{\text {у }}<(1.2-1.3) \sigma_{\text {т. }}$ The nature of the influence of cavitation depends on the shape of the pressure pulsation. Strongly developed cavitation leads to disruption of regular pulsations and an increase in the swing of the highfrequency component. When $\sigma_{\mathrm{y}},>1.3 \sigma_{\text {т }}$ pressure pulsation does not depend on the magnitude.

4. The complexity of the composition, the high cost of high-alloy steels and nonferrous alloys make it irrational to use them in massive parts operating under cavitationabrasive conditions. Therefore, ordinary cast iron, cast bronze, and heavy plate steel are used, which have low cavitation-abrasive resistance.

5. It is recommended to use the developed dependencies and requirements to assess energy-saving possibilities and reduce deterioration by improving the quality of the materials of the impellers at machine water lifting systems and other hydraulic structures.

\section{References}

1. Bazarov, D.R. and others. Mathematical modeling of control of the operation mode of the Amu-Bukhara machine channel, International academy journal "Web of Scholar", 1 (19), Vol.1, Warsaw, Poland, 00-773, pp. 26-32. January (2018)

2. Mukhammadiev MM, Dzhuraev KS, and Klychev ShI Capabilities of Hydroelectric Pumped-Storage Stand-Alone Power Plants. International journal "Applied Solar Energy", Vol. 49, No. 4, pp. 267-271. (2013)

3. Glovatsky O.Ya. R.R.Ergashev Reliability assessment and measures for resourcessaving on water lifting engine systems in the republic of Uzbekistan // Journal «Perspectives of Innovations, Economics and Businnes», - Prague, -Volume 4. Issue 1. - pp. 111-113. (2010).

4. Karelin V.Ya. Wear of vane pumps, M .: Mechanical engineering. - pp.168. (1983).

5. O.Glovatskiy, T. Djavburiyev, Z. Urazmukhamedova, A. Gazaryan, F.Akhmadov Interconnection of influent channel and pumping station units, XXII International Scientific Conference on Advanced in Civil Engineering / construction the formation of living environment, (2019)

6. Khokhlov V.A., Titova J.O. Energy Saving and Safe Operating Modes of the Large Irrigative Pumping Stations, Handbook of Research on Renewable Energy and Electric Resources for Sustainable Rural Development. IGI Global, USA, pp. 176203. (2018).

7. F.Bekchanov, R.Ergashev, T.Mavlanov, O.Glovatskiy Mathematical model of vibrating air pump unit, XXII International Scientific Conference on Advanced in Civil Engineering / construction the formation of living environment, pp.18-21, (2019) 
8. Jarkovsky A., Freedom D.G. Design of the flow section of an axial pump with a nonfalling pressure characteristic. Hydraulic machines, hydraulic drives and hydropneumatic automation. Current state and development prospects ": Collection of scientific papers of the IRTC. - SPb .: Publishing house of Polytechnic. un-ta, - p. 168175, (2018)

9. Glovatsky O.Ya., Nosirov F.Zh., Sharipov Sh.M., Saparov A.B. Study of the influence of cavitation on the pressure pulsation behind the impeller of pumping units // Collection of scientific articles of the XV scientific-practical conference of young scientists and masters "Modern problems in agriculture and water management", "Qishlova suv khjaligining zamonaviy muammolari" - pp.425 -430. Tashkent, (2016).

10. Glovatskiy O.Ya., Nasyrova NR, Berdiyarov A.E. Study of cavitation-abrasive wear of irrigation pumps // Collection of scientific articles of the XV scientific-practical conference of young scientists and masters "Modern problems in agriculture and water management", "Modern problems of agriculture and water management"- pp.433-436. Tashkent, (2016)

11. A.I.Djurabekov, Sh.R.Rustamov, O.Y. Glovatsky Mechanism of cavitation and hydroabrasive wear of centrifugal pumps of irrigation pumping stations, Sb. scientific works, SIC ICWC of Central Asia, -. pp. 153-159. Tashkent, (2017)

12. Glovatskiy O. Ya., Sharipov Sh.M., Saparov A.B. Influence of hydraulic losses on the cavitation qualities of non-stationary processes of pumping units, Collection of scientific articles of the XV scientific-practical conference of young scientists and masters "Contemporary problems in agriculture and water management", "Modern problems of agriculture and water management" - pp.491-494, Tashkent, (2016)

13. Jarkovskiy A., Ivanov E.A., Borshchev I.O. Improvement of hydraulic and pulsation characteristics of multi-stage centrifugal pumps Nauchno-tehnicheskie vedomosti SPbPU. Natural and engineering sciences. 2018. T. 24. № 3. pp. 126-138.

14. Bazarov D., Markova I., Raimova I., Sultanov Sh. Water flow motion in the vehicle of main channels. IOP Conf. Ser. Mater. Sci. Eng. 883, 012025 (2020).

15. Jarkovskiy A., Zhurkin, N., Donskoj, A. Numeric modeling and estimating the performance characteristics of a pneumatic driven high pressure pump(2018) MATEC Web of Conferences, 245, article № 09014, DOI: 10.1051/matecconf/201824509014

16. Jarkovskiy A., Svoboda, D.G., Ivanov, E.A.. Influence of the Geometric Parameters of the Impeller of a Free-Vortex Pump on the Energy and Cavitation Characteristics of the Pump Chemical and Petroleum Engineering, Springer US, Vol. 54, Nos. 9-10, January, (2019), pp. 673-680 DOI: 10.1007/s10556-019-00532-w.

17. Matyakubov B., Begmatov I., Raimova I. and Teplova G. Factors for the efficient use of water distribution facilities. IOP Conf. Ser. Mater. Sci. Eng. 883, 012025 (2020).

18. Uralov B., Rakhmatov N., Khidirov S., Uljaev F., Raimova I. Hydraulic modes of damless water intake. IOP Conf. Ser. Mater. Sci. Eng. 1030(1), 012123 (2021)

19. F.Bekchanov, R.Ergashev, T.Mavlanov, O.Glovatskiy Mathematical model of vibrating air pump unit, XXII International Scientific Conference on Advanced in Civil Engineering / construction the formation of living environment, pp.18-21, April, (2019).

20. Oleg Glovatsky, Rustam Ergashev, Azamat Saparov, Mustafo Berdiev and Bobur Shodiev Cavitation-abrasive wear working collectors of pumps, IOP Conference Series: Materials Science and Engineering (2020) 869042006.

21. Obidov B., Vokhidov O., Tadjieva D., Kurbanova, U., Isakov A. Hydrodynamic effects on the flow elements of the downstream devices in the presence of cavitation. IOP Conf. Ser. Mater. Sci. Eng. 1030, 012114 (2021).

22. Bazarov D., Norkulov B., Vokhidov O., Uljaev F., Ishankulov, Z. Two-dimensional flow movement in the area of protective regulatory structures. IOP Conf. Ser. Mater. 
Sci. Eng. 890, 012162 (2020)

23. E.Kan, M.Mukhammadiev, N.Ikramov. Methods of regulating the work of units at irrigation pumping stations. IOP Conference Series: Materials Science and Engineering, Volume 869, (2020) 042009.

24. M. Mukhammadiev, A. Nasrulin, A. Mukolyants, D. Ergasheva A complexly method of GIS technologies and optimization models used in the development of environmentally acceptable modes of operation of hydraulic and hydropower facilities in Uzbekistan, International Scientific Conference Mathematical Modelling and Methods of Structural Analysis (2019) Moscow State University of Civil Engineering (MGSU). Moscow, Russia IOP Conf. Series: Journal of Physics: Conf. Series 1425 (2020) 012132 doi: 10.1088./1742-6596/1/0121132.

25. Bazarov D., Vatin N., Obidov B., and Vokhidov O. Hydrodynamic effects of the flow on the slab of the stand in the presence of cavitation. IOP Conf. Ser. Mater. Sci. Eng. 1030, 012110 (2021).

26. Bazarov D., Markova I., Norkulov B. and Vokhidov O. Hydraulic aspects of the layout of head structures during water intake from lowland rivers. IOP Conf. Ser. Mater. Sci. Eng. 1015, 012041 (2021).

27. Bazarov D., Markova I., Sultanov S. and Kattakulov F. Dynamics of the hydraulic and alluvial regime of the lower reaches of the Amudarya after the commissioning of the Takhiatash and Tuyamuyun hydrosystems. IOP Conf. Ser. Mater. Sci. Eng. 1030, 012110 (2021).

28. Bazarov D. and Vokhidov O. Extinguishing Excess Flow Energy in Spillway Structures. In book: Proceedings of EECE 2020, LNCE 150, pp. 535-545, (2021) DOI: 10.1007/978-3-030-72404-7_52

29. Bazarov D., Markova I., Norkulov B., Isabaev K., Sapaeva M. Operational efficiency of water damless intake. IOP Conf. Ser. Mater. Sci. Eng. 869(7), 072051, (2020)

30. Fay C. Theoretische Grundlagen der Modelgesetze und Umrechnung der Messergebnisse an Uberdriickturbine, Budapest, (1998).

31. Krutov A., Choriev R., Norkulov B., Mavlyanova D. and Shomurodov A. Mathematical modelling of bottom deformations in the kinematic wave approximation. IOP Conf. Ser. Mater. Sci. Eng. 1030, 012147 (2021).

32. Krutov A., Norkulov B., Uljaev F., and Jamalov F. Results of a numerical study of currents in the vicinity of a damless water intake. IOP Conf. Ser. Mater. Sci. Eng. 1030, 012121 (2021).

33. Krutov A., Norkulov B., Mavlyanova D. Simulation of spreading of non-conservative passive substances in water bodies. IOP Conf. Ser. Mater. Sci. Eng. 883(1), 012028 (2020)

34. Krutov A., Norkulov B., Nurmatov P., Mirzaev M. Applicability of zero-dimensional equations to forecast nonconservative components concentration in water bodies. IOP Conf. Ser. Mater. Sci. Eng. 883(1), 012028 (2020)

35. Krutov A., Norkulov B., Artikbekova F., Nurmatov P. Optimal location of an intake at a reservoir prone to salt diffusion. IOP Conf. Ser. Mater. Sci. Eng. 869(7), 072020, (2020)

36. Shokirov B., Norkulov B., Nishanbaev Kh., Khurazbaev M., Nazarov B. Computer simulation of channel processes. E3S Web of Conferences, 97, 05012, (2019)

37. Hubert G. Untersuchungen uber die Sekundarverluste in axialen Turbomaschinen. VDI - Forsch. - Heft 496, (2003). 